\title{
EQUILIBRIUM OF A JOURNAL BEARING: A SIMPLIFIED CFD-ANALYTICAL COUPLED APPROACH
}

\author{
FRANCO CONCLI \\ Faculty of Science and Technology, Free University of Bolzano/Bozen, Italy
}

\begin{abstract}
Journal bearings are historically designed using the half-Sommerfeld theory. The semi-analytical solution of the continuity and momentum conservation equations is used as the starting point. Possible negative values of the pressure were substituted with the ambient pressure. This hypothesis provides acceptable results, even if for a better understanding of the phenomena cavitation effects should be considered and modelled numerically. The authors have already proved the capability to achieve very accurate results with the Kunz cavitation model. The numerical results were validated in terms of pressure distribution with experimental data coming from different setups. In this paper, a simplified CFD-analytical coupled approach for the calculation of the equilibrium position and its trajectory of the journal is shown.
\end{abstract}

Keywords: journal bearing, hybrid CFD-analytical approach, simulation, trajectory.

\section{INTRODUCTION}

Journal bearings are mechanical components designed to support shaft. They can carry (mainly) radial loads. Their load-carrying capacity derives from pressures that arise in the convergent/divergent clearance of a journal bearing. Even if both the journal and the ring are cylindrical, during operation their axes are not coaxial. This causes a very high pressure in the convergent clearance and a successive pressure drop after the smallest clear opening size. The pressure drop is however physically limited by the vaporization pressure $\left(p_{v}\right)$. This physical property of the lubricant discriminates by the liquid phase of the oil and its vapor phase. After reaching the vaporization value, in fact, the pressure cannot decrease anymore before all the liquid is completely transformed into vapor. This fact produces an unbalance in the pressure and, consequently, the supporting effect.

The first works on journal bearings was carried out by Sommerfeld [1] in 1904. He solved the Reynold's equations for an infinite bearing. This work was successively elaborated by Swift [2]. This solution is valid for long bearings ( $/ \mathrm{D}>>1)$. The pressure distribution is therefore considered constant in the axial direction. Moreover, the analytical solution is possible only assuming that the convergent/divergent is fully lubricated. Cavitation and pressure limitation due to vaporization effects are not considered. The solution results therefore in a symmetric distribution in which the pressure drops significantly under the physical limit $p_{v}$. These models predict that the equilibrium position of the journal lies directly below the bearing center. However, this result has been proven to be wrong [3] and never observed experimentally.

Therefore, the full-Sommerfeld theory was improved leading to the so-called halfSommerfeld film condition proposed by Gumbel [4] in 1914. The negative pressures were artificially substituted by mean of the vaporization pressure. Fig. 1 shows an example of results achievable with the full- and the half-Sommerfeld models in terms of pressure distribution on the journal.

Dowson [6] proposed an empirical approach to artificially correct the full-Sommerfeld results. 


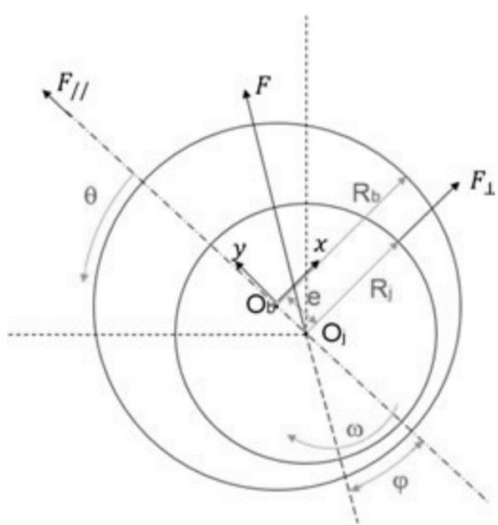

(a)

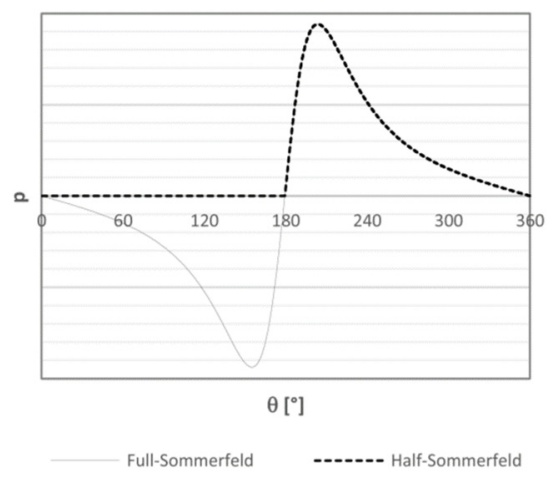

(b)

Figure 1: (a) Schematic layout of a journal bearing under load ( $\mathrm{Rb}$ bearing radius, $\mathrm{Rj}$ journal radius, $\varphi$ attitude angle, e eccentricity and $\omega$ rotational speed); and (b) Full-Sommerfeld and half-Sommerfeld pressure distribution. (Source: Adapted from [5].)

More recently, with the increasing computational performances, more and more numerical approaches were presented. Mane and Soni [7] and Chauhan et al. [8] used CFD techniques to overcome the $2 \mathrm{D}$ approximation and consider the tridimensional effects. However, their models still neglect vaporization and a correction of the results in order to avoid having negative pressures was required. A similar work was presented by Gao et al. [9] using water instead of lubricant. Gandjalikhan Nassab et al. [10] compared their numerical results with the experimental data by Pan and Vohr [11]. The work of Gandjalikhan Nassab relies on the Heshmat [12] hypothesis of keeping the pressure constant in the cavity region. Other numerical analysis where presented by several authors. Among them Sawicki and Rao [13] and Riedel et al. [14] which compared the results with the experimental ones by Jakobsson and Floberg [3] and Vijayaraghavan and Keith [15] respectively.

More recently, the author has presented a full 3D numerical approach that includes the vaporization effects. The model was developed in the OpenFOAM ${ }^{\circledR}$ [16] environment. Different cavitation models, e.g. Kunz et al. [17], Merkle et al. [18], Liebrecht et al. [19], [20] and Gonda et al. [21], were tested. The results were compared with those measured by Gao et al. and by Jakobsson. The model was capable to predict the pressure distribution with an error of less than 5\%. However, the computational cost of considering the vaporization effects lead to an increase of the computational effort by 350 times with respect to the fulllubricated 3D simulation (which results should be corrected artificially to avoid negative pressures). This latter model, despite the very low computational effort, is capable to predict the pressure distribution with an error of about $10 \%$ only. Considering that the aim of this work is to predict the trajectory of the journal, the leaner full-lubricated model was selected as the most appropriate one.

\section{MATERIALS}

The bearing studied in this research is a small journal bearing. The journal radius is equal to $2 \mathrm{~mm}$ and a radial clearance equal to $10 \mu \mathrm{m}$. The axial width is $13 \mathrm{~mm}(\mathrm{~L} / \mathrm{D}>>1$ ). The average rotational speed is equal to $328 \mathrm{rad} / \mathrm{s}$. The mass of the journal itself is $1.30710^{-3} \mathrm{~kg}$. 
However, the study was performed considering an additional mass (shaft) ranging from 0.05 to $1 \mathrm{~kg}$.

The lubricant used is a Kluebersynth $\mathrm{GH} 6-22$ with a density at $15^{\circ} \mathrm{C}$ equal to $\rho_{15^{\circ} \mathrm{C}}=1,060 \mathrm{~kg} / \mathrm{m}^{3}$ and a viscosity that results equal to $\eta_{40^{\circ} \mathrm{C}}=220 \mathrm{e}^{-6} \mathrm{~m}^{2} / \mathrm{s}$ at $40^{\circ} \mathrm{C}$ and $\eta_{100^{\circ} \mathrm{C}}=40 \mathrm{e}^{-6} \mathrm{~m}^{2} / \mathrm{s}$ at $100^{\circ} \mathrm{C}$.

\section{METHODS}

A hybrid CFD-analytical [22]-[24] approach was used.

\subsection{Computational fluid dynamics}

CFD [25] was used to model the bearing and to simulate the drag and lift forces for a given rotational speed and a different eccentricities. Simulations were performed in the open-source environment OpenFOAM ${ }^{\circledR}[26]$.

The method used is based on Finite Volumes (FV) [27]. The computational domain is discretized into small cells. Specifically, it was subdivided in about 4,000 hexahedrons (ten elements in the radial direction) (Fig. 2).

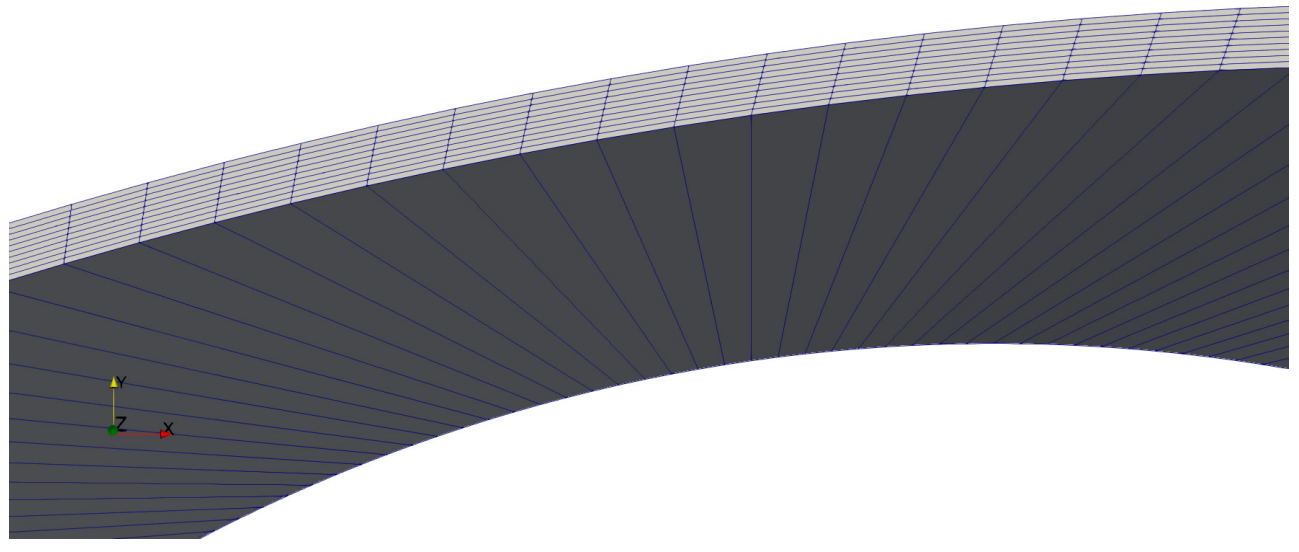

Figure 2: Detail of the mesh of the journal bearing.

To each cell balancing equations are applied: the mass conservation and the momentum conservation [28]

$$
\begin{gathered}
\frac{\partial \rho}{\partial t}+\nabla(\rho \boldsymbol{v})=0, \\
\frac{\partial \rho}{\partial t}+\nabla(\rho \boldsymbol{v} \boldsymbol{v})=-\nabla p+\nabla\left[\mu\left(\nabla \boldsymbol{v}+\nabla \boldsymbol{v}^{T}\right)+\rho \boldsymbol{g}+\boldsymbol{F},\right.
\end{gathered}
$$

where $\rho$ is the lubricant density, $\boldsymbol{v}$ is the velocity vector, $p$ is the pressure, $\boldsymbol{g}$ is the gravitational acceleration and $\boldsymbol{F}$ the vector of the external forces. The energy conservation was not activated, and the fluid considered isothermal. The mean temperature was set acting on the properties of the fluid. The density at a certain temperature $\theta$ was calculated with the following equation [29]

$$
\rho_{\theta}=\rho_{15^{\circ} \mathrm{C}}-(\theta-15) \cdot 0.0007
$$


while the viscosity was determined using a logarithmic relation between the known viscosity values at $40^{\circ} \mathrm{C}$ and $100^{\circ} \mathrm{C}$.

With the present approach, the fluid is regarded as a continuum and its behavior is described by means of its macroscopic properties.

The PDE are discretized into algebraic equations and solved using a PIMPLE (merged PISO-SIMPLE) scheme. The PIMPLE scheme combines the structure of the SIMPLE algorithm allowing the under-relaxation and a fast convergence of the solution with the velocity correction loops that are typically of the PISO mode.

Simulations were performed for different levels of eccentricity and the results reported in terms of drag and lift forces.

Fig. 3 shows the pressure and velocity fields.
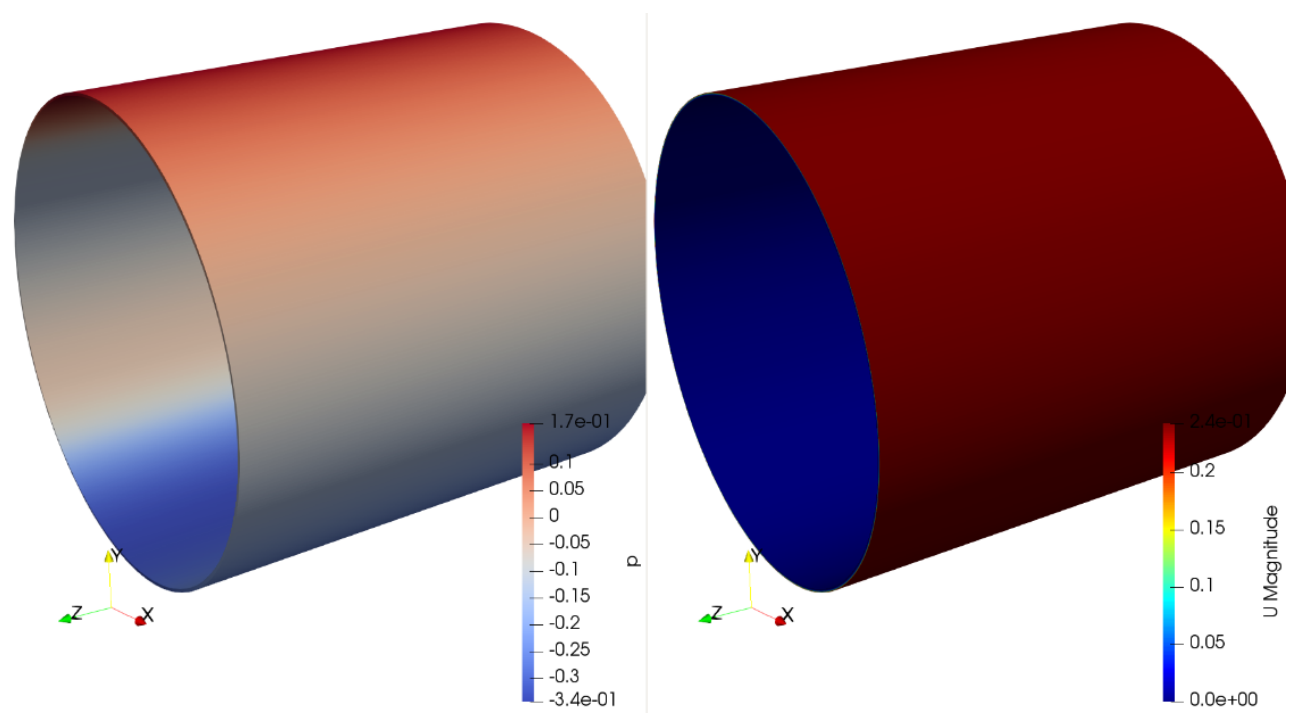

Figure 3: CFD results: Pressure and velocity contours.

Figs 4 and 5 show the force and the attitude angle for different eccentricities and a rotational speed of $328 \mathrm{rad} / \mathrm{s}$. The relation is clearly not linear. These data will be used successively for the calculation of the trajectory of the journal.

\subsection{Dynamics}

Starting from the results obtained from the CFD model, a force balance (Newton equation) was used to calculate the equilibrium position and the trajectory of the journal.

In addition to the fluid dynamic forces $\left(\boldsymbol{F}_{C F D}\right)$, gravitational- $(\boldsymbol{g} \cdot m)$ and inertial-effects $(\boldsymbol{a} \cdot m)$ should be considered

$$
\sum \boldsymbol{F}=\boldsymbol{F}_{C F D}+m \cdot \boldsymbol{a}+m \cdot \boldsymbol{g}=0 .
$$

$\boldsymbol{F}_{C F D}$ and $\boldsymbol{g}$ are known both in terms of direction and magnitude. Consequently, the acceleration $\boldsymbol{a}$ can be calculated. The final equilibrium position of the journal can be therefore calculated together with the trajectory. After a given time $d t$, the new equilibrium position can be calculated from the actual one knowing the corresponding displacement $\boldsymbol{S}$ 


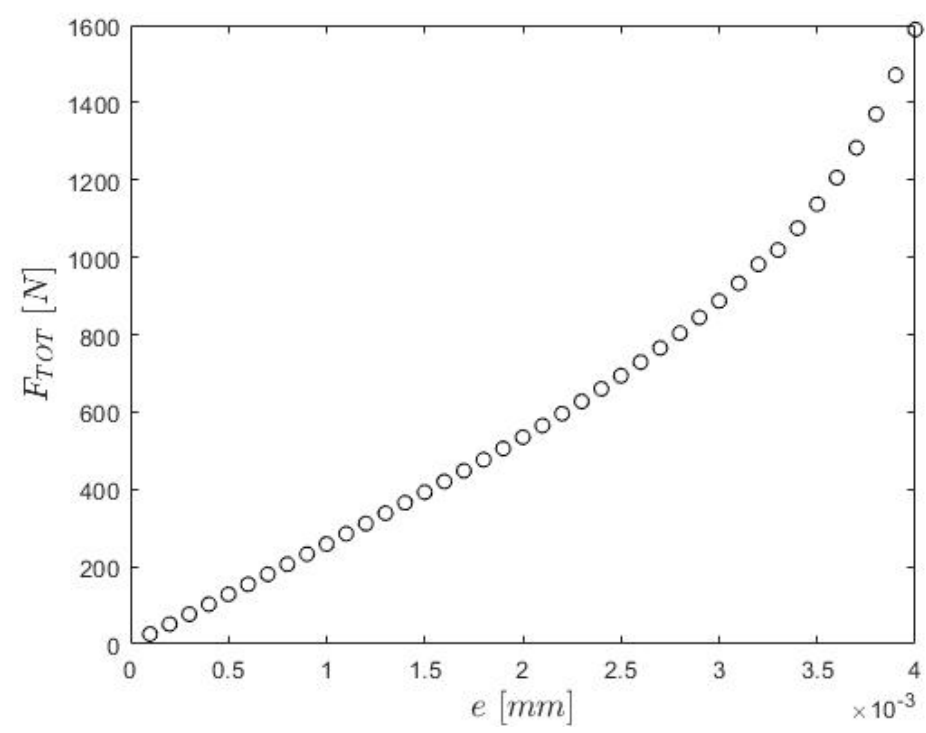

Figure 4: Total hydraulic force versus eccentricity: $328 \mathrm{rad} / \mathrm{s}$.

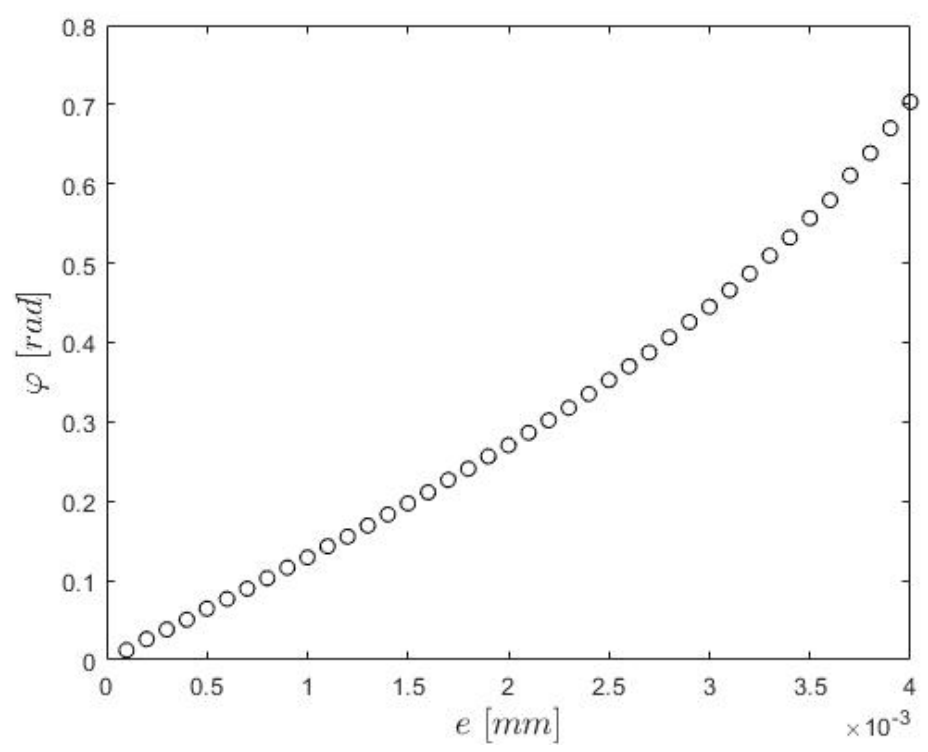

Figure 5: Attitude angle versus eccentricity: $328 \mathrm{rad} / \mathrm{s}$.

$$
\boldsymbol{s}=\frac{\boldsymbol{F} \cdot d t^{2}}{m}
$$

The calculations were performed in the open-source software Scilab [30].

Figs 6-9 show the trajectories of the journal from the geometrical center of the bearing $(x=0, y=0)$ to the equilibrium position for different external load and operating conditions. 


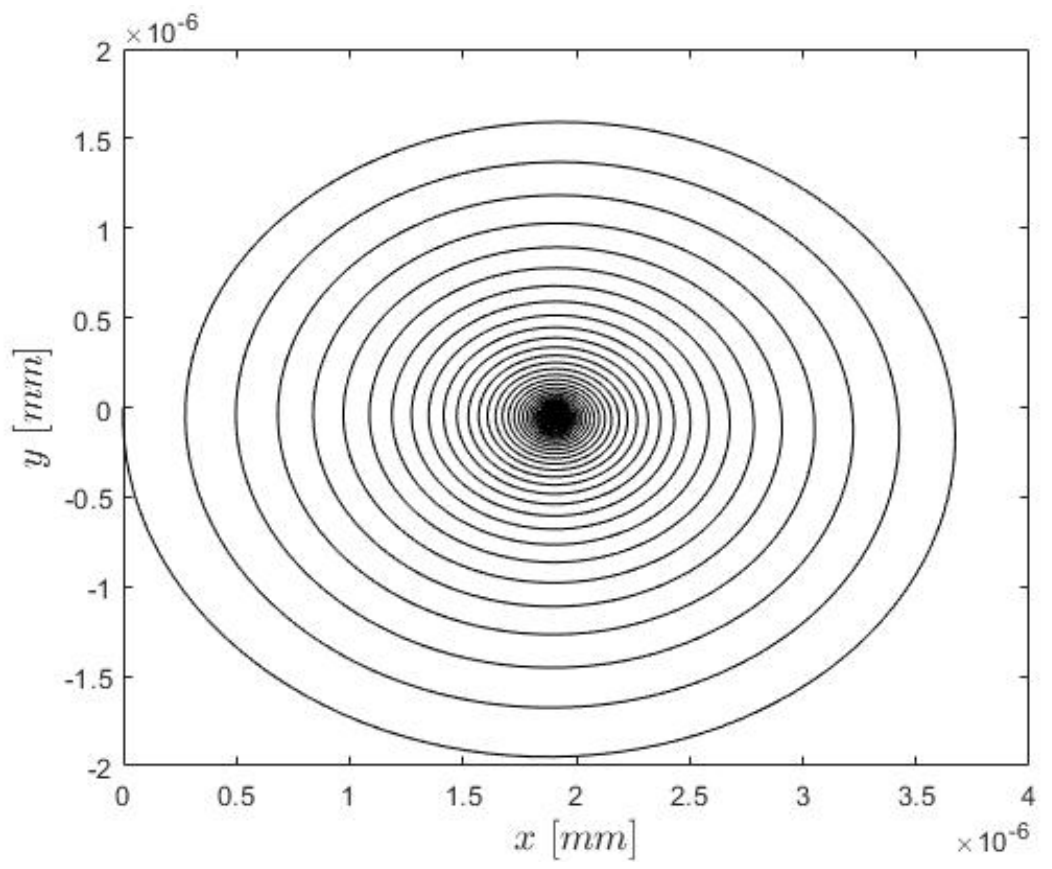

Figure 6: Trajectory of the journal: $0.05 \mathrm{~kg}-328 \mathrm{rad} / \mathrm{s}$.

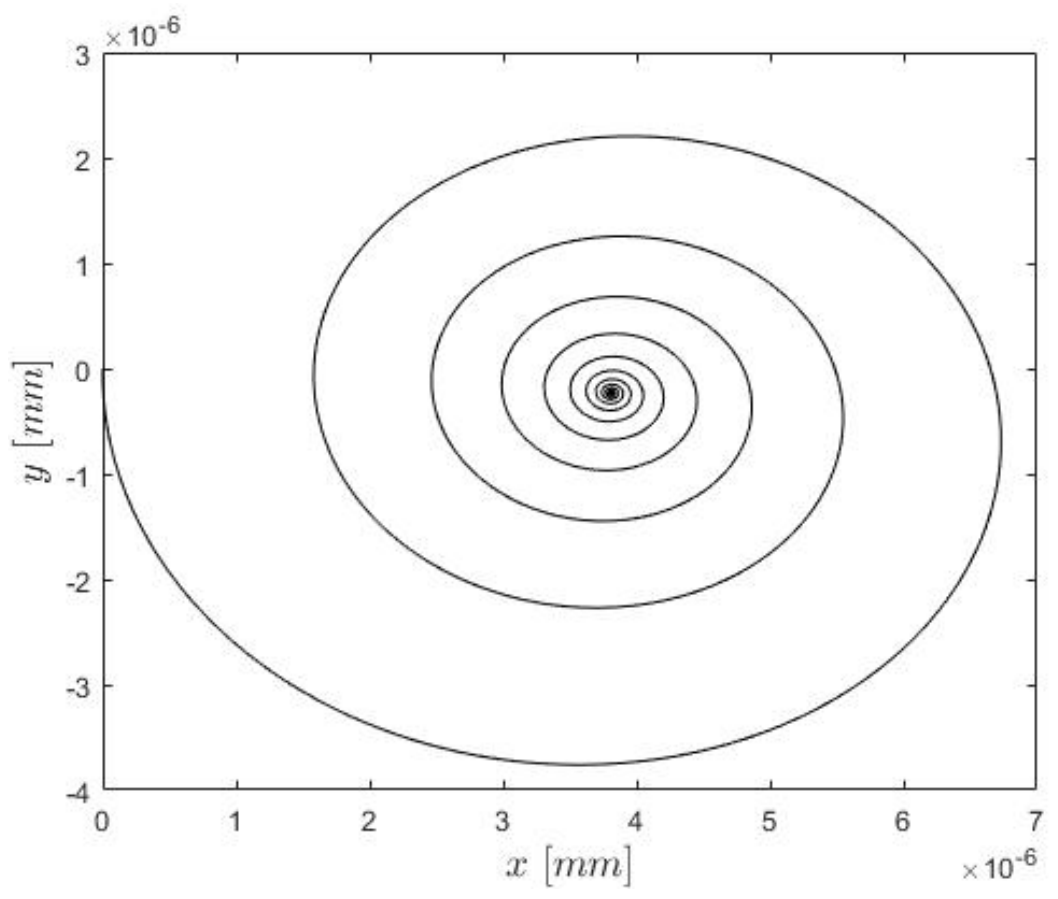

Figure 7: Trajectory of the journal: $0.1 \mathrm{~kg}-328 \mathrm{rad} / \mathrm{s}$. 


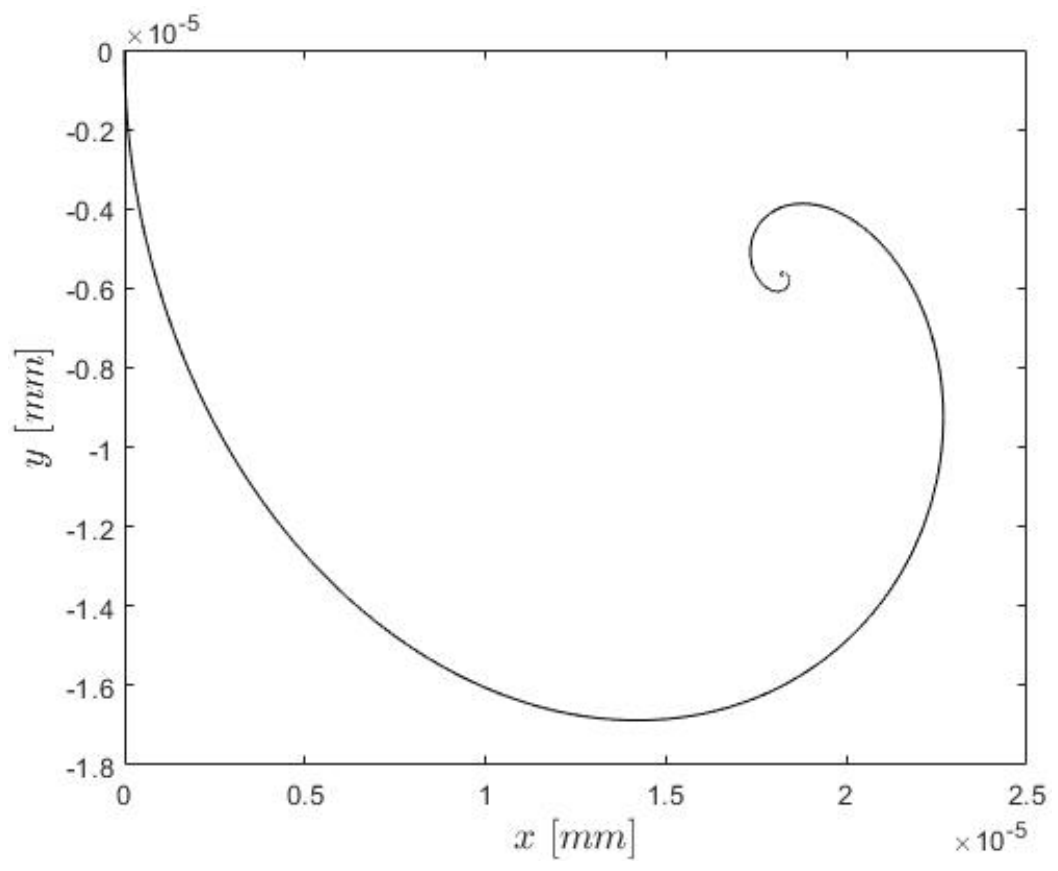

Figure 8: Trajectory of the journal: $0.5 \mathrm{~kg}-328 \mathrm{rad} / \mathrm{s}$.

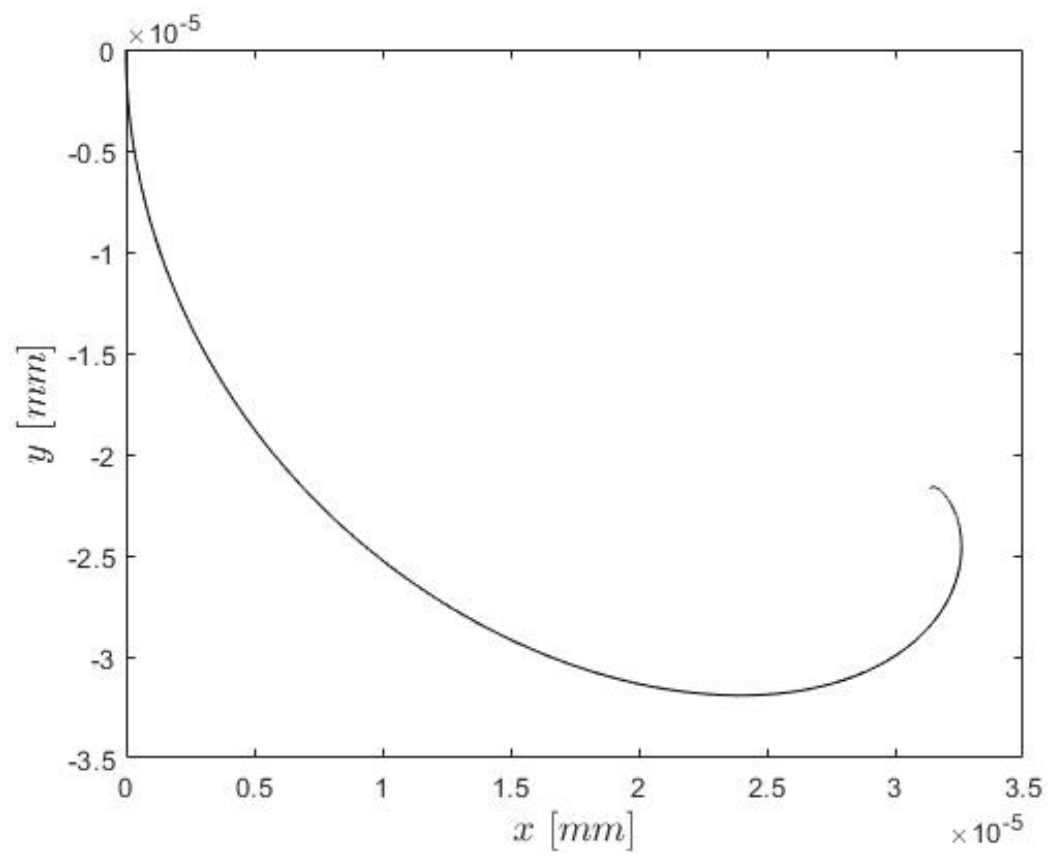

Figure 9: Trajectory of the journal: $1 \mathrm{~kg}-328 \mathrm{rad} / \mathrm{s}$. 
Figs $10-13$ show the variation of the eccentricity versus time.

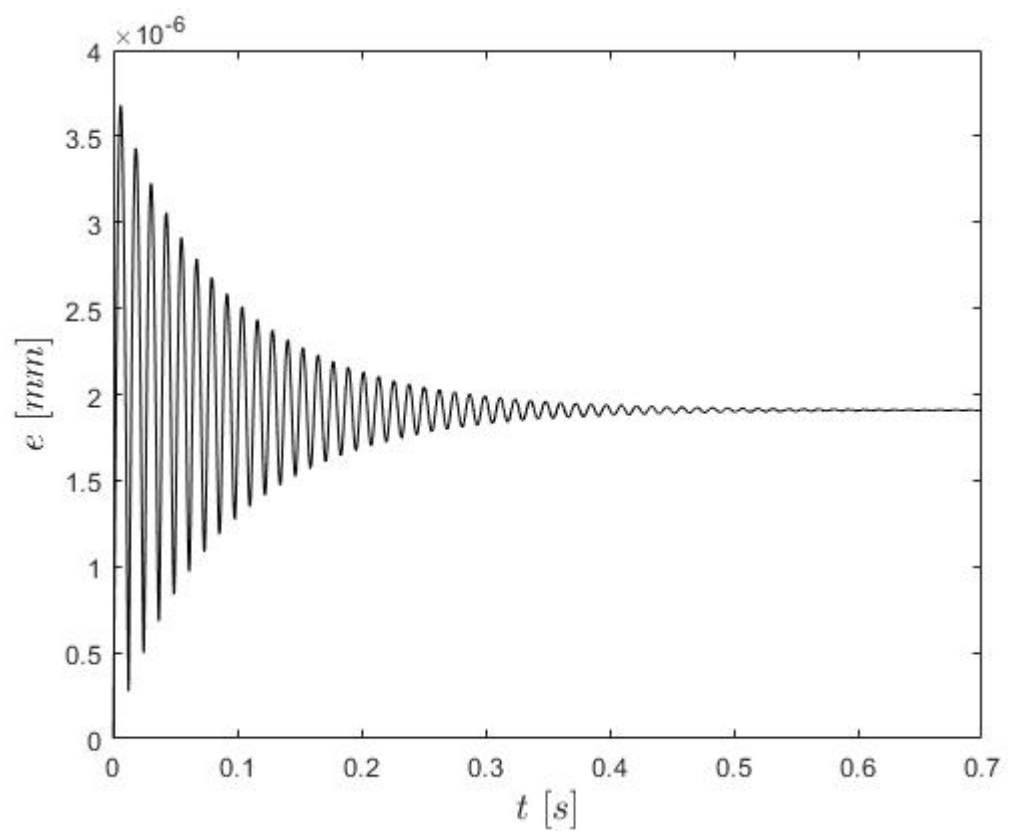

Figure 10: Eccentricity versus time: $0.05 \mathrm{~kg}-328 \mathrm{rad} / \mathrm{s}$.

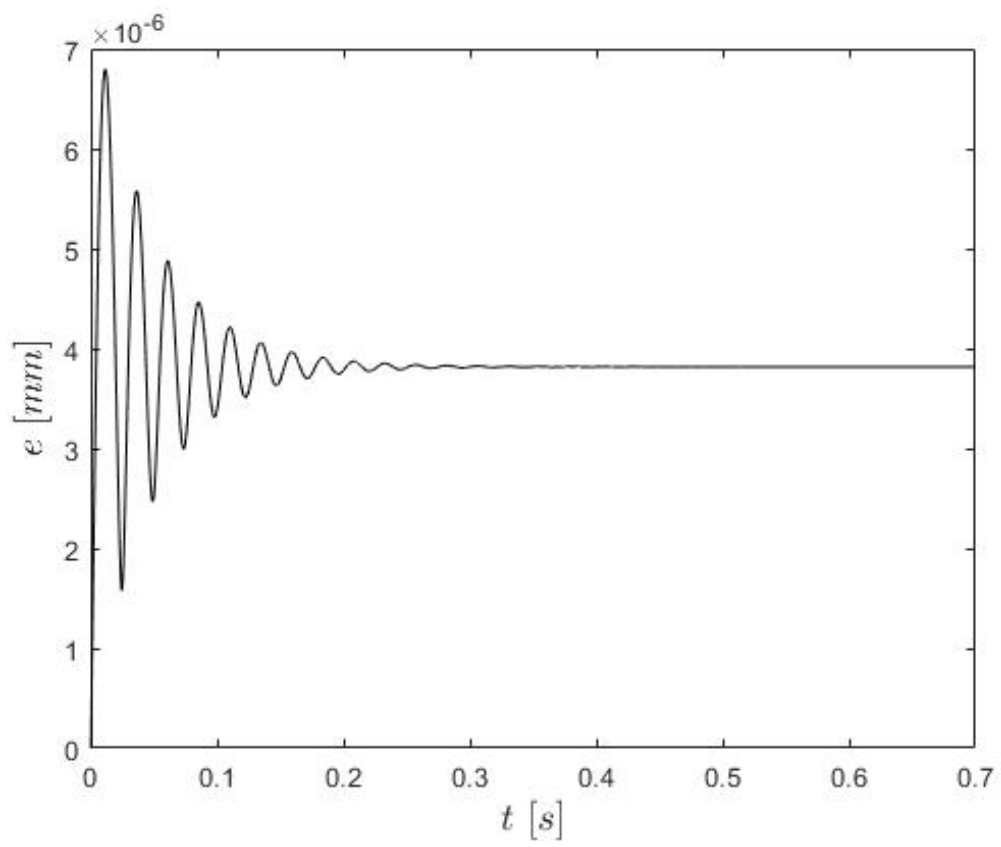

Figure 11: Eccentricity versus time: $0.1 \mathrm{~kg}-328 \mathrm{rad} / \mathrm{s}$. 


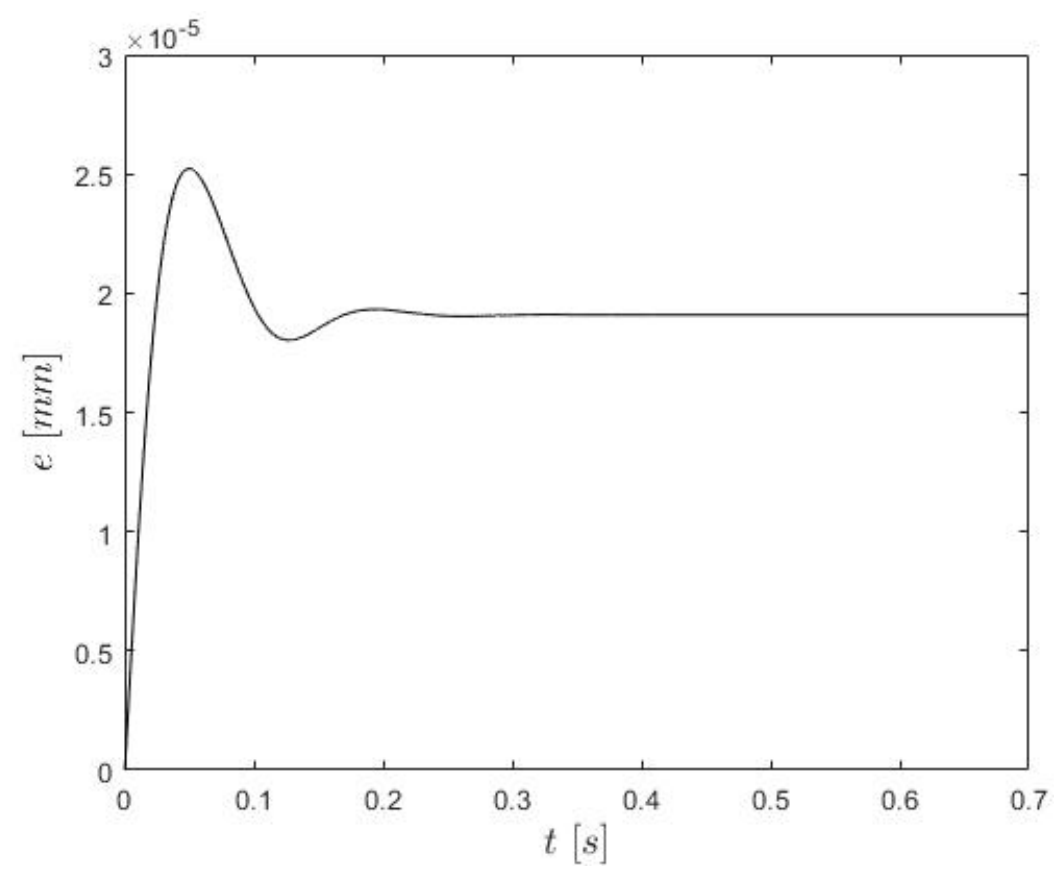

Figure 12: Eccentricity versus time: $0.5 \mathrm{~kg}-328 \mathrm{rad} / \mathrm{s}$.

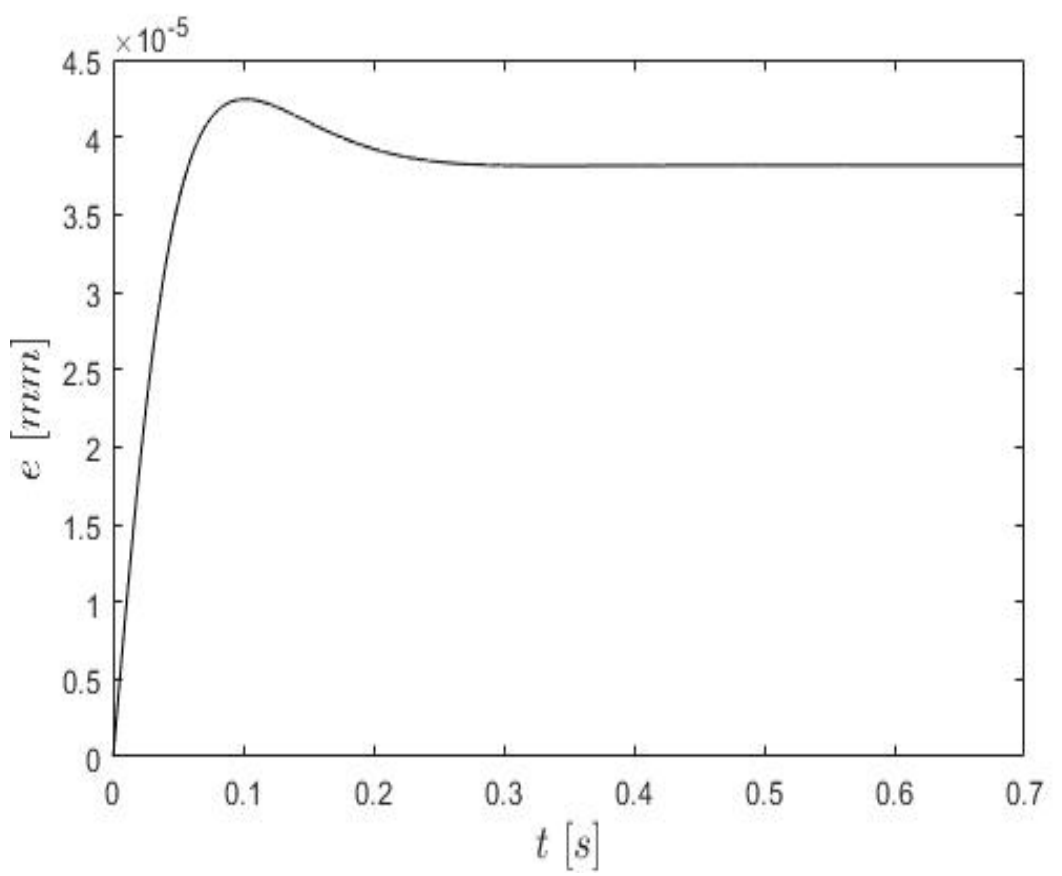

Figure 13: Eccentricity versus time: $1 \mathrm{~kg}-328 \mathrm{rad} / \mathrm{s}$. 


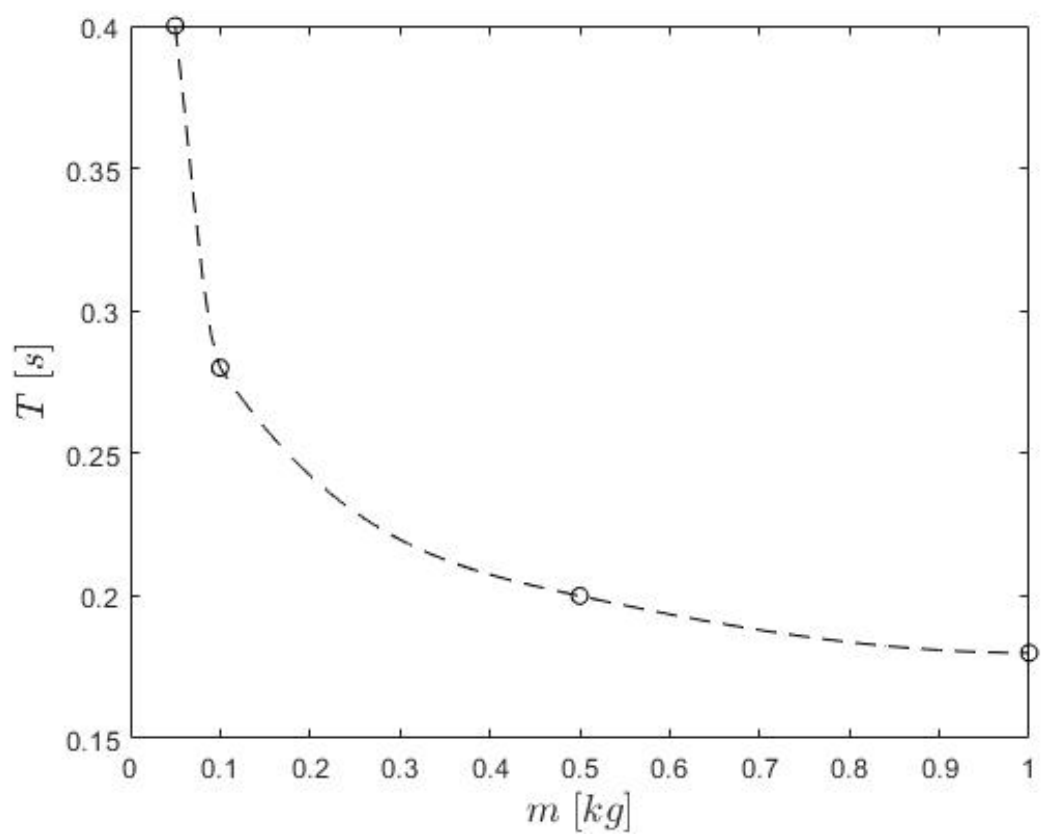

Figure 14: Stabilization time versus journal mass: $328 \mathrm{rad} / \mathrm{s}$.

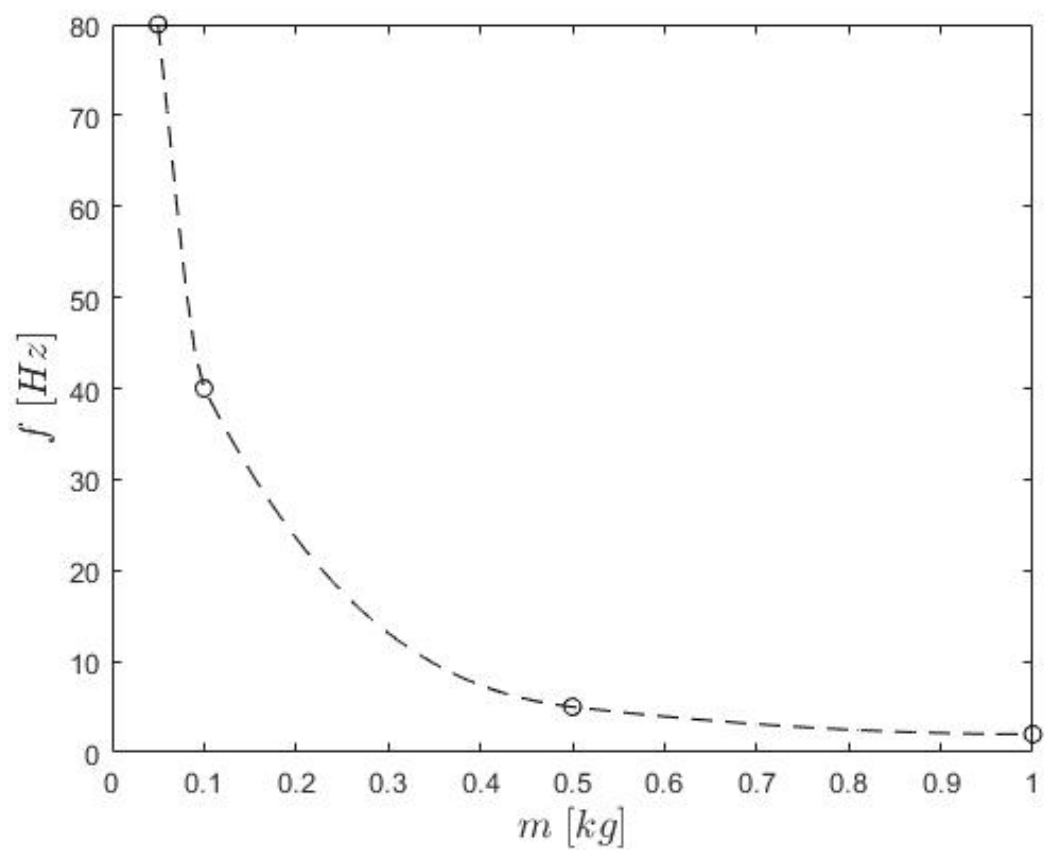

Figure 15: Excitation frequency versus journal mass: $328 \mathrm{rad} / \mathrm{s}$. 
It can be clearly observed that the equilibrium position did not lies on the vertical axis but is slightly shifted also laterally. This effect is well known and occurs due to the cavitation that produces an unbalance of the pressures between the convergent and the divergent gaps.

The equilibrium position is significantly depending on the mass of journal ( 0.05 to $1 \mathrm{~kg})$. Moreover, also the duration $\mathrm{T}$ of the transitory is related to the mass. Higher values of mass imply a higher acceleration and offset from the geometrical center of the bearing (Fig. 14). A higher eccentricity is in turn related to higher viscous forces coming from the fluid that produces a bigger damping effect. Therefore, the time required for reaching the equilibrium position reduces. At the same time, the oscillating frequency decreases as well. The knowledge of the frequencies are important for a preliminary evaluation of the Noise Vibration Harshness (NVH) behavior of the bearing. The starting phase, in fact, promotes the excitation of different frequencies $\mathrm{f}$ (Fig. 15) that can interact with the eigenfrequencies of the system causing noise and undesired vibrations. For the studied configurations, the excited frequencies results in the range $2-80 \mathrm{~Hz}$.

\section{PERFORMANCE ENHANCHMENTS}

The CFD simulations were performed in the open-source OpenFOAM ${ }^{\circledR}$ environment. Each simulation (for a specific eccentricity) took approximately 150 seconds on a 12 GFLOPS hardware. The solution of the Newton equation was performed in the open-source software Scilab with an effort of few seconds. The method results therefore lean and could be potentially very interesting for engineers in the design phase.

\section{CONCLUSION}

This paper a hybrid approach is shown, which combines the numerical solution of the Reynolds equations of fluid dynamics with an analytical approach for the solution of the Newton equation for the force balance. The procedure leads not only to the equilibrium position but also the trajectory, the stabilisation time and the excited frequencies. This latter information can be very useful for having an indication about the NHV behaviour of the system during the start-up. The approach has been developed coupling an open-source CFD code - OpenFOAM ${ }^{\circledR}$ - and Matlab. In addition to the equilibrium position and the trajectory from the start up to the regime condition, the model also provides the pressure distribution both on the surfaces of the journal and the ring as well as the pressures and velocity fields of the lubricant mixture. This model is therefore a powerful tool to better design new bearings on the basis of a deep understanding of the physics of the system.

\section{ACKNOWLEDGEMENT}

This work is supported by the project RTD 2018 - SMOG funded by the Free University of Bozen-Bolzano (PI: Franco Concli).

\section{REFERENCES}

[1] Sommerfeld, A., The hydrodynamic theory of lubrication friction. Zeitschrift für Math. und Phys., 97, p. 50, 1904.

[2] Swift, H.W., The full journal bearing. Proc. Inst. C.E., 233, p. 267, 1931.

[3] Jakobsson, B. \& Floberg, L., The finite journal bearing, considering vaporization [Das Gleitlager von endlicher Breite mit Verdampfung]. Mater. Sci., 1957.

[4] Gumbel, L., Monatsblatter Berlin, Bezirksver, 1914.

[5] Concli, F., Pressure distribution in small hydrodynamic journal bearings considering cavitation: A numerical approach based on the open-source CFD code OpenFOAM ${ }^{\circledR}$. Lubr. Sci., 28(6), pp. 329-347, 2016. 
[6] Dowson, D., A generalized Reynolds equation for fluid-film lubrication. Int. J. Mech. Sci., 4(2), pp. 159-170, 1962.

[7] Mane, R.M. \& Soni, S., Anal. Hydrodyn. Plain J. Bear., 2013.

[8] Chauhan, A., Singla, A., Panwar, N. \& Jindal, P., CFD based thermo-hydrodynamic analysis of circular journal bearing. J. Adv. Mech. Eng., 4(5), pp. 475-482, 2014.

[9] Gao, G., Yin, Z., Jiang, D. \& Zhang, X., Numerical analysis of plain journal bearing under hydrodynamic lubrication by water. Tribol. Int., 75, pp. 31-38, 2014.

[10] Gandjalikhan Nassab, S.A., Hohi, H. \& Zaim, E.H., Study of lubricant compressibility effect on hydrodynamic characteristics of heavily loaded journal bearings. Iran. J. Sci. Technol. Trans. B Eng., 35(M1), pp. 101-105, 2011.

[11] Pan, C.T.H. \& Vohr, J.H., Super Laminar Flow Bear. Seals, Bear. Seals Des. Nucl. Power Mach., pp. 219-245, 1967.

[12] Heshmat, H., The mechanism of cavitation in hydrodynamic lubrication. Tribol. Trans., 34(2), pp. 177-186, 1991.

[13] Sawicki, J.T. \& Rao, T.V., Cavitation effects on the stability of a submerged journal bearing. Int. J. Rotating Mach., 10(3), pp. 227-232, 2004.

[14] Riedel, M., Schmidt, M. \& Stuecke, P., Numer. Investig. Cavitation Flow J. Bear. Geom., 2013.

[15] Vijayaraghavan, D. \& Keith, J.T.G., Development and evaluation of a cavitation algorithm. Tribol. Trans., 32(2), pp. 225-233, 1989.

[16] OpenFOAM, User Guide. www.openfoam.com. Accessed on: 15 Jul. 2019.

[17] Kunz, R.F. et al., A preconditioned Navier-Stokes method for two-phase flows with application to cavitation prediction. Comput. Fluids, 29(8), pp. 849-875, 2000.

[18] Merkle, C.L., Feng, J. \& Buelow, P.E.O., Computational modeling of the dynamics of sheet cavitation. 3rd Int. Symp. Cavitation, pp. 307-311, 1998.

[19] Liebrecht, J., Si, X., Sauer, B. \& Schwarze, H., Investigation of drag and churning losses on tapered roller bearings. Stroj. Vestnik/Journal Mech. Eng., 61(6), pp. 399$408,2015$.

[20] Liebrecht, J., Si, X., Sauer, B. \& Schwarze, H., Technical-mathematical approach for the calculation of the flow and churning losses in tapered roller bearings [Technischmathematischer Ansatz zur Berechnung der Plansch-und Strömungsverluste am Kegelrollenlager]. Tribol. und Schmierungstechnik, 63(4), pp. 5-13, 2016.

[21] Gonda, A., Großberndt, D., Sauer, B. \& Schwarze, H., Experimental and numerical investigations of hydraulic losses in rolling bearings under practice-oriented conditions [Experimentelle und numerische untersuchungen der hydraulischen verluste in Wälzlagern unter praxisrelevanten Bedingungen]. Tribol. und Schmierungstechnik, 65(6), pp. 7-13, 2018.

[22] Concli, F., Low-loss gears precision planetary gearboxes: Reduction of the load dependent power losses and efficiency estimation through a hybrid analyticalnumerical optimization tool. Forsch. im Ingenieurwesen/Engineering Res., 2017.

[23] Concli, F., Cortese, L., Vidoni, R., Nalli, F. \& Carabin, G., A mixed FEM and lumpedparameter dynamic model for evaluating the modal properties of planetary gearboxes. J. Mech. Sci. Technol., 32(7), pp. 3047-3056, 2018.

[24] Concli, F., Thermal and efficiency characterization of a low-backlash planetary gearbox: An integrated numerical-analytical prediction model and its experimental validation. Proc. Inst. Mech. Eng. Part J J. Eng. Tribol., 230(8), pp. 996-1005, 2016.

[25] Concli, F. \& Gorla, C., A CFD analysis of the oil squeezing power losses of a gear pair. Int. J. Comput. Methods Exp. Meas., 2(2), pp. 157-167, 2014. 
[26] Concli, F., Gorla, C., Torre, A.D. \& Montenegro, G., Windage power losses of ordinary gears: Different CFD approaches aimed to the reduction of the computational effort. Lubricants, 2(4), pp. 162-176, 2014.

[27] Concli, F. \& Gorla, C., CFD simulation of power losses and lubricant flows in gearboxes. American Gear Manufacturers Association Fall Technical Meeting 2017, 2017.

[28] Concli, F. \& Gorla, C., Influence of lubricant temperature, lubricant level and rotational speed on the churning power loss in an industrial planetary speed reducer: Computational and experimental study. Int. J. Comput. Methods Exp. Meas., 1(4), pp. 353-366, 2013.

[29] Concli, F., Maccioni, L. \& Gorla, C., Lubrication of gearboxes: CFD analysis of a cycloidal gear set. WIT Transactions on Engineering Sciences, vol. 123, WIT Press: Southampton and Boston, pp. 101-112, 2019.

[30] www.Scilab.org. 